\title{
Conduction mechanism in doped polymethyl methacrylate (PMMA) films
}

\author{
P K KHARE*, S K JAIN ${ }^{\dagger}$ and S K PALIWAL \\ Department of Postgraduate Studies and Research in Physics, Rani Durgavati Vishwa- \\ vidyalaya, Jabalpur 482001 , India \\ ${ }^{\dagger}$ Central Instrumentation Lab, Dr H S Gaur University, Sagar 470 003, India \\ MS received 26 August 1996; revised 6 January 1997

\begin{abstract}
The electrical transport behaviour of ferrocene mixed poly (methyl methacrylate) (PMMA) films ( $\approx 20 \mu \mathrm{m}$ in thickness) deposited by the isothermal immersion technique has been studied in the temperature range of $333-373 \mathrm{~K}$ and field from $(2.0-4.0) \times 10^{4} \mathrm{~V} / \mathrm{cm}$. It has been found that at higher fields and temperatures, the observed conduction behaviour could be consistently described by the Richardson-Schottky emission. The increase in current due to doping has been attributed to the formation of charge transfer complexes. The dopant molecules act as an additional trapping centre and provide a link between polymer molecules in amorphous region leading to the formation of charge transfer complex.
\end{abstract}

Keywords. Conduction mechanism; polymethyl methacrylate; ferrocene; RS effect; charge transfer complex.

\section{Introduction}

The study of electrical conduction of insulating and semiconducting materials sandwiched between metal electrodes is becoming popular on account of the possibility of memory phenomenon (Kryezewski 1975) in them and their use in thin film device (Mead 1961). Although many investigations have been made of electrical conduction in polymers (Zor and Hogarth 1987; Narsimha Rao et al 1988; Ahmad and Zihilip 1992), difficulties in measurement of physical quantities related to the charge transfer and complexity of the polymer structure are making the clearcut understanding of its mechanism difficult. A considerable amount of work has been reported on steady state electrical conduction in impurity doped polymers (Tiwari et al 1980; Chand and Mahendru 1986; Chakraborty et al 1991; Khare and Srivastava 1991, 1992; Khare 1994; Khare et al 1994a), which has resulted in steady progress in understanding the nature of complex formation between the polymer and dopant. Depending on their chemical structure and the way in which they react with the macromolecular matrix, doping substances decrease the resistivity of the polymer to different degrees. Poly (methyl methacrylate) (PMMA) is an amorphous polar polymer having a high impact strength. Ferrocene, a nonpolar, inorganic monomer (Phadke et al 1978) selected as dopant is a $\pi$-bonded cyclopentadiene complex, well known for its various electrical properties (Khare et al 1994c; Khare and Chandok 1995). The present investigation on ferrocene mixed poly (methyl methacrylate) films has been undertaken with a view to understand in better terms the nature of the electrical conduction mechanism and the effect of impurity doping on it.

* Author for correspondence 


\section{Experimental}

The polymer used in the present work was a commercial grade polymethyl methacrylate. Ferrocene was procured from $\mathrm{M} / \mathrm{s}$ Chemical Agencies, Bombay, India. It is a $\pi$-bonded, orange coloured, non-polar crystalline solid. It is a cyclopentadyene complex having molecular formula $\mathrm{C}_{10} \mathrm{H}_{10} \mathrm{Fe}$ in which an iron atom is sandwiched (Dunitz and Orgel 1953) between two cyclopentadyene anions. The $\mathrm{Fe}-\mathrm{C}$ bonds have a small amount $(12 \%)$ of ionic character. Isothermal immersion technique was utilized for preparing thin films of ferrocene mixed PMMA. The solution of a particular concentration was prepared in a glass beaker by first dissolving $2.1 \mathrm{~g}$ PMMA in $30 \mathrm{ml}$ of chloroform at room temperature and ferrocene $(20 \mathrm{mg}, 40 \mathrm{mg}$ and $60 \mathrm{mg}$ ) was added to the polymer matrix in weight quantities. A change in colour of doped films from white to yellow was noticed. The solution was continuously stirred for $30 \mathrm{~min}$ by means of a teflon-coated magnetic stirrer. Thereafter, it was stirred and heated up to $313 \mathrm{~K}$ to yield a homogeneous solution. The glass beaker containing the solution was then immersed in a constant temperature oil bath. Ultrasonically cleaned vacuum metallized microscopic glass slides were immersed vertically into the solution for a period of about $30 \mathrm{~min}$. After deposition of film, the glass slide was taken out and dried in an oven at $313 \mathrm{~K}$ for $24 \mathrm{~h}$. This was followed by room temperature outgassing at 133.33 Newton $/ \mathrm{m}^{2}$ for a further period of $24 \mathrm{~h}$. Upper metal electrode was also vacuum deposited. The thickness of the sample was of the order of $20 \mu \mathrm{m}$, which was estimated by measuring the capacitance of the fabricated sandwiches taking the value of dielectric constant $\varepsilon$ of PMMA as 3 . The steady state conduction current was recorded as a function of applied field and temperature as reported earlier (Khare et al 1993). The measurements were carried out with the poling fields ranging from $(2-4) \times 10^{4} \mathrm{~V} / \mathrm{cm}$ at temperatures ranging from $333-373 \mathrm{~K}$.

\section{Results and discussion}

Figure 1 shows the current-voltage $(I-V)$ characteristics at various temperatures for $\approx 20 \mu \mathrm{m}$ thick films. It is evident from these curves that for all the temperatures, two regions of conduction, i.e. an ohmic region of conduction with value of slope $m \approx 1$ at lower fields $\left(<3.0 \times 10^{4} \mathrm{~V} / \mathrm{cm}\right)$ and a non ohmic region with slope $\approx 1.7-1.9$ at higher fields $\left(>3.0 \times 10^{4} \mathrm{~V} / \mathrm{cm}\right)$ are observed. The effect of temperature on $I-V$. characteristics may be explained as follows. With the increase of temperature, the probability of thermal ionization of the trapping centres increases thus causing a shift in the quasi fermi level which gives rise to a lowering of the barrier across which the electrons have to be transported and the conduction becomes more or less ohmic (Khare et al 1993). The ohmic behaviour can be understood on the basis of the reasonable assumption that at lower fields the injection of carriers from the contact is less and the initial current is governed by the intrinsic free carriers in the material. The current will be ohmic until the injected free carrier density becomes comparable with the thermally created carrier density. However, at sufficiently higher fields the current is mainly due to injected space charge and the conduction is space charge limited (Khare et al 1994b, d).

Thin polymer films are known to be a mixture of amorphous and crystalline regions (Chopra et al 1971). The conductivity behaviour of such films may be dominated by the properties of the amorphous regions (Kosaki et al 1971). The presence of amorphous regions gives rise to localized states. Since there are many localized states, the release or 


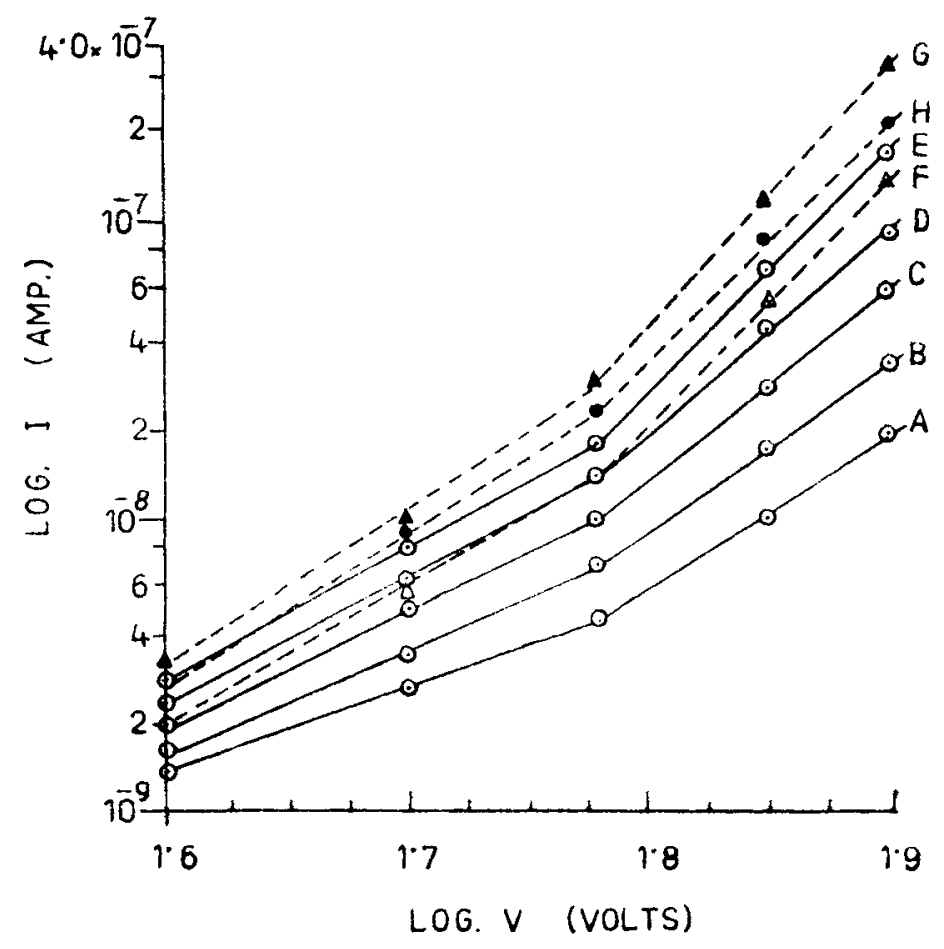

Figure 1. Plots of $\log I$ vs $\log V$ for ferrocene $(20 \mathrm{mg})$ mixed PMMA films at different temperatures (A) $T=333$; (B) 343; (C) 353; (D) 363 and (E) $373 \mathrm{~K}$. Curves F, G and $\mathrm{H}$ correspond to 40,60 and $80 \mathrm{mg}$ ferrocene respectively at $333 \mathrm{~K}$.

excitation of the carriers in these states dominates the conduction process. Consequently, doping should not affect the conductivity too much (Sinha and Srivastava 1979) unless the dopant is present in sufficient quantity to markedly affect the position of the Fermi level. Dopant molecules enter either the amorphous regions of the polymer or the defect regions like chain folds. If they are present in low concentration, they will give rise to additional molecular sites for trapping of charge carriers. Such localized sites can be defined in molecular terms using the difference in ionization potential as an indication of trap depth. As the dopant concentration is increased, the molecules start bridging the gap separating the two localized states and lowering the potential barrier between them, thereby facilitating the transfer of charge carriers (Khare et al 1994d; Sinha and Srivastava 1979). The approximate dopant concentration used in the present case is in the range $9.3,18.6$ and $27.9 \mathrm{wt} \%$ which indicates the relative concentration of ferrocene in polymer matrix. The order of conduction current in the case of pure PMMA (Khare and Srivastava 1991) is $10^{-11}$ A, while that for doped samples (in the present case) it is $10^{-6} \mathrm{~A}$. Further, the steady state current value is also higher for doped PMMA. These observations suggest that ferrocene introduces donor levels which get localized, giving rise to extrinsic charge carriers and charge traps. If the insulator contains a large number of donor levels, there are many free carriers available in the insulator conduction band and it shows a high conductivity (Khare and Srivastava 1991). Current is found to increase as the concentration of ferrocene is increased. However, into further increase in dopant concentration $(>60 \mathrm{mg}$ ) i.e. for $80 \mathrm{mg}$, the 
increase in conduction slows down. The effect of ferrocene concentrations on conduction currents and associated activation energy values has been given in table 2 . Increase in the concentration of ferrocene in the polymer matrix increases the anisotropy which may be responsible for the creation of new trapping sites (Perlman 1971). This agrees with the earlier findings (Khare et al 1994c). It is reasonable to assume that molecules of ferrocene may occupy the interstitial sites between the polymer chains of amorphous phase and link them with some type of bonds due to charge transfer processes between ferrocene and ester group of PMMA. The other possible role of ferrocene impregnation with PMMA may be, to develop excess charges in the polymer matrix. The conductivity of the system is enhanced either due to increase in carrier concentration or their mobility, or both. It seems that chain motion is not effective in mobilizing the traps formed by dopant molecules and that charge carriers released from mobilized traps are subsequently trapped in traps provided by dopant molecular sites. When the dopant concentration is further increased the carrier mobility increases and at the optimum dopant concentration $(60 \mathrm{mg})$ the conductivity reaches its maximum value. This behaviour may occur because CTC are formed in the polymer and these effectively decrease the trapping effects by handing on the carriers (Sinha and Srivastava 1979; Sinha et al 1981). When sufficient dopant molecules are present (at the optimum dopant concentration) links between trapping centres are produced because of the increase in the number of orbital overlaps. A further increase in the dopant concentration ( $>60 \mathrm{mg}$ ) does not increase the conductivity because steric effects place a serious limit on the degree to which the conductivity can be enhanced by the formation of CTC. Our present results are in good agreement with this view.

The high field electronic conduction in polymer films is commonly discussed in terms of one of the following processes: space charge limited conduction (SCLC), Richardson-Schottky (RS) emission, Poole-Frenkel (PF) emission, and tunnelling of carriers into or via traps. In order to establish the dominant mode of conduction in a particular material, one has to look into the detailed analysis of $I-V$ data of the material in terms of the theoretical considerations available for different types of processes. The Schottky emission is analogous to thermionic emission as it involves charge emission from the metal electrode with the difference that the barrier height is lowered by the reduction in the metal insulator work function due to the applied electric field. The P-F mechanism, however, involves the thermal excitation of electrons from traps into the conduction band of the insulator. The restoring force in both $\mathrm{R}-\mathrm{S}$ and $\mathrm{P}-\mathrm{F}$ effects is due to coulomb interaction between the escaping electron and positive charge, they however differ in that the positive image charge is fixed for $\mathrm{P}-\mathrm{F}$ barriers, but mobile with Schottky emission. An increase in electric field reduces the Coulomb potential of trapped charge carriers in its direction and increases the possibility of the thermal excitation of charge carriers into the conduction band of the insulator giving rise to non-ohmic characteristics (Khare 1994; Khare et al 1994d).

To determine the actual conduction mechanism, the experimental value of $\beta$, at different temperatures deduced from the $\log I$ vs $E^{1 / 2}$ plots (figure 2) are compared with the theoretical values. The $\beta_{\text {exp }}$ values are nearer with those of $\beta_{\mathrm{RS}}$ rather than those of $\beta_{\mathrm{PF}}$ suggesting thereby that RS mechanism is the dominant mode of conduction. It is difficult to draw a definite conclusion from the coincidence of $\beta$-values alone. It may not be a satisfactory evidence for deciding the conduction mechanism. The proper way of distinguishing between the $\mathrm{P}-\mathrm{F}$ and Schottky mechanisms was suggested by Jonscher and Ansari (1971). The effect of electrode materials namely aluminium, silver and 


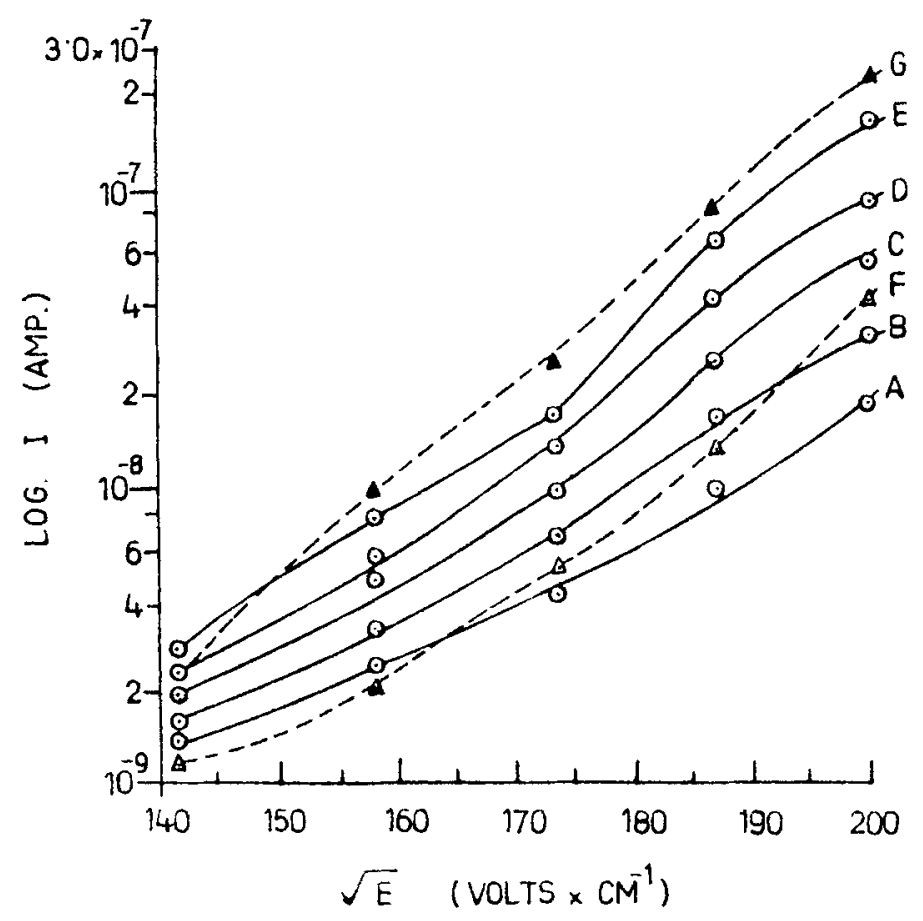

Figure 2. Plots of $\log I$ vs $\log E^{1 / 2}$ for ferrocene $(20 \mathrm{mg}$ ) mixed PMMA films at different temperatures (A) $T=333$; (B) 343; (C) 353; (D) 363 and (E) $373 \mathrm{~K}$ (Al-Al system). Curves $\mathrm{F}$ and G correspond to $\mathrm{Al}-\mathrm{Ag}, \mathrm{Al}-\mathrm{Cu}$ electrode combinations respectively (at $333 \mathrm{~K}$ ).

copper on the $I-V$ characteristics has to be considered to decide the conduction mechanism. Figure 2 shows the $I-V$ characteristics for doped PMMA at $343 \mathrm{~K}$ with dissimilar metal electrodes. The current through the samples (at a particular temperature) differs when the upper aluminium electrode is replaced by silver and copper. Different lines were obtained for $\mathrm{Al}-\mathrm{Al}, \mathrm{Al}-\mathrm{Cu}$ and $\mathrm{Al}-\mathrm{Ag}$ combinations. The magnitude of current was found to be higher in dissimilar electrode combinations (Al-Cu and $\mathrm{Al}-\mathrm{Ag}$ ). This shows that the current is controlled by the effective work function of metal-insulator-metal interfaces. The differences between the work function of metal (1) and metal (2) will control the electrode ( $\mathrm{Al}-\mathrm{Al}$ ) systems, the characteristics of the polymer may prevail as the net contribution to current from charges injected from the electrodes would then be zero (Khare and Srivastava 1993). These observations are consistent with the proposed RS mechanism and suggest that in doped PMMA films are governed by the RS effect in which the carriers are injected over the field dependent polymer-electrode interfacial barrier. The effective metal potential barriers for different electrodes have been calculated from the slope of $\log J / T^{2}$ vs $1 / k T$ plots (results not shown) at a constant field of $2.5 \times 10^{4} \mathrm{~V} / \mathrm{cm}$ (table 1 ). It is interesting to note that these plots are straight line in agreement with RS mechanism. The activation energy values for different electrode systems used were calculated from the plots of $\log I$ vs $10^{3} / T$ (figure 3 ) and are also listed in table 1 . These values are very close to the experimentally determined metal-insulator effective potential barrier obtained for different electrode materials. This again suggests that the dominant charge carrier 
Table 1. Theoretical and experimental values of $\beta$ activation energy, effective potential barrier for ferrocene $(20 \mathrm{mg})$ mixed PMMA films.

\begin{tabular}{llllllll}
\hline $\begin{array}{l}\text { Temperature } \\
(\mathrm{K})\end{array}$ & $\begin{array}{l}\beta_{\mathrm{RS}} \\
\left(\times 10^{-2}\right)\end{array}$ & $\begin{array}{l}\beta_{\mathrm{PF}} \\
\left(\times 10^{-2}\right)\end{array}$ & $\begin{array}{l}\beta_{\text {exp }} \\
\left(\times 10^{-2}\right)\end{array}$ & $\begin{array}{l}\text { Metal } \\
\text { electrodes }\end{array}$ & $\begin{array}{l}\text { Metal } \\
\text { work } \\
\text { function }\end{array}$ & $\begin{array}{l}\text { Effective Activation } \\
\text { potential energy } \\
\text { barrier }\end{array}$ & $\begin{array}{l}\text { eV }) \\
(\mathrm{eV}\end{array}$ \\
\hline 333 & 1.968 & 3.936 & 2.213 & Aluminium & 3.38 & 0.61 & 0.63 \\
343 & 1.873 & 3.746 & 2.011 & Copper & 4.46 & 0.73 & 0.75 \\
353 & 1.796 & 3.592 & 1.987 & Silver & 4.41 & 0.88 & 0.89 \\
363 & 1.644 & 3.288 & 1.898 & & & & \\
373 & 1.598 & 3.196 & 1.789 & & & & \\
\hline
\end{tabular}

Table 2. Effect of ferrocene concentrations on conduction currents and activation energy values ( $\mathrm{Al}-\mathrm{Al}$ electrode system; $\mathrm{T}=333 \mathrm{~K}$ ).

\begin{tabular}{llllll}
\hline & \multicolumn{5}{c}{ Ferrocene concentrations } \\
\cline { 2 - 5 } & $20 \mathrm{mg}$ & $40 \mathrm{mg}$ & $60 \mathrm{mg}$ & $80 \mathrm{mg}$ \\
\hline 1. Conduction currents & & & & \\
(a) At $E_{\mathbf{P}}=2.0 \times 10^{4} \mathrm{~V} / \mathrm{cm}$ & $1.5 \times 10^{-9} \mathrm{~A}$ & $2.0 \times 10^{-9} \mathrm{~A}$ & $3.6 \times 10^{-9} \mathrm{~A}$ & $3.0 \times 10^{-9} \mathrm{~A}$ \\
(b) At $E_{\mathbf{P}}=4 \cdot 0 \times 10^{4} \mathrm{~V} / \mathrm{cm}$ & $2.0 \times 10^{-8} \mathrm{~A}$ & $1.5 \times 10^{-7} \mathrm{~A}$ & $3.8 \times 10^{-7} \mathrm{~A}$ & $2.0 \times 10^{-7} \mathrm{~A}$ \\
2. Activation energy $(\mathrm{eV})$ & 0.63 & 0.60 & 0.58 & 0.57 \\
\hline
\end{tabular}

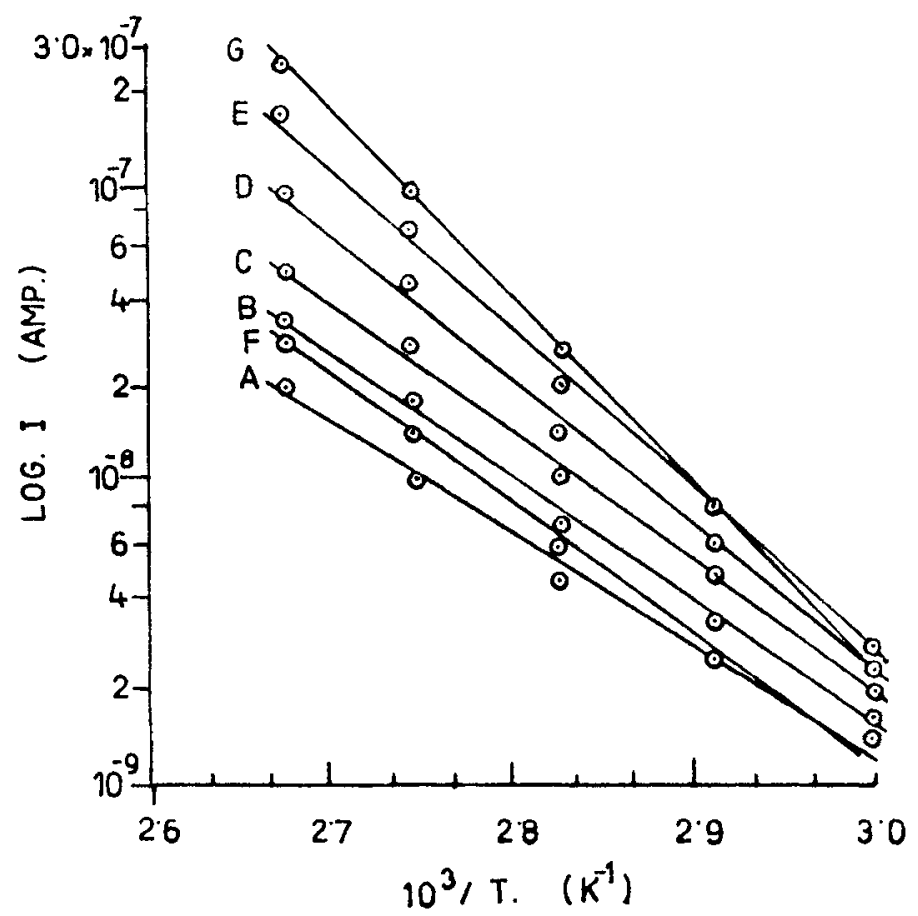

Figure 3. Plots of $\log I$ vs $10^{3} / T$ for ferrocene $(20 \mathrm{mg})$ mixed PMMA films. Curves A, B, C, $\mathrm{D}$ and $\mathrm{E}$ correspond to $\mathrm{Al}-\mathrm{Al}$ system and curves $\mathrm{F}$ and $\mathrm{G}$ corresponds to $\mathrm{Al}-\mathrm{Ag}$ and $\mathrm{Al}-\mathrm{Cu}$ electrode combinations respectively. 
mechanism in this case is of Richardson-Schottky type. However, the possibility of trapping of charge carriers in shallow traps cannot be ruled out because the activation energy values are slightly higher than the effective metal-insulator potential barrier (Khare and Srivastava 1991).

\title{
References
}

\author{
Ahmad M S and Zihilip A H 1992 Polym. Comp. 1353 \\ Chopra K L, Rastogi A C and Malhotra G L 1971 Thin Solid Films 24125 \\ Chand S and Mahendru P C 1986 J. Phys. D19 857 \\ Chakraborty S C, Palit N B, Das S K and Basu S 1991 Indian J. Pure \& Appl. Phys. 29478 \\ Dunitz J D and Orgel L E 1953 Nature 171121 \\ Jonscher A K and Ansari A A 1971 Philos. Mag. 23205 \\ Khare Pavan and Srivastava A P 1991 Indian J. Pure \& Appl. Phys. 29410 \\ Khare P K 1994 Indian J. Pure \& Appl. Phys. 32160 \\ Khare P K and Srivastava A P 1991 Thin Solid Films 208233 \\ Khare P K and Srivastava A P 1993 Indian J. Pure \& Appl. Phys. 31126 \\ Khare P K and Chandok R S 1995 J. Polym. Mater. Sci. 1223 \\ Khare P K, Gaur M S, Alka Bajpai, Pandey R K and Srivastava A P 1993 Indian J. Pure \& Appl. Phys. 31326 \\ Khare P K, Gaur M S and Srivastava A P 1994a Indian J. Pure \& Appl. Phys. 3214 \\ Khare P K, Srivastava S and Srivastava A P 1994b Indian J. Phys. A68 129 \\ Khare P K, Chandok R S, Dubey N and Srivastava A P 1994 c Polym. Int. 35153 \\ Khare P K, Keller J M, Gaur M S, Singh Ranjeet and Datt S C 1994d Polym. Int. 35337 \\ Kosaki M, Sugiyama K and Ieda M 1971 J. Appl. Phys. 423388 \\ Kryezewski M 1975 J. Polym. Sci. Polym. Symp. USA 50359 \\ Mead C A 1961 J. Appl. Phys. USA 32646 \\ Narsimha Rao V V R, Mahaender T and Subba Rao B 1988 J. Non-Cryst. Solids 104224 \\ Perlman M M 1971 J. Appl. Phys. 422645 \\ Phadke Shirish D, Sathi Nandan and Karekar R N 1978 Thin Solid Films 27 L-11 \\ Sinha H C and Srivastava A P 1979 Indian J. Pure \& Appl. Phys. 17726 \\ Sinha H C, Talwar I M and Srivastava A P 1981 Thin Solid Films 82229 \\ Tiwari A R, Shrivastava S K, Saraf K K and Srivastava A P 1980 Thin Solid Films 70191 \\ Zor M and Hogarth C A 1987 Phys. Status Solidi 99513
}

